\title{
THE INFLUENCE OF STORE ATMOSPHERE AND LOCATION ON PURCHASE DECISION AT PUSRI MART SEMARANG AREA
}

\author{
Ayu Sa’idah, Suryadi Poerbo², Fatchun Hasyim \\ Jurusan Administrasi Bisnis, Politeknik Negeri Semarang, Semarang, Indonesia \\ email: ${ }^{2}$ suryadi poerbo@polines.ac.id
}

\begin{abstract}
The purpose of this study are analize the influence of store atmosphere and location on purchase decision at Pusri Mart area Semarang. The data collection technique are questionnaires, interview, observation, and literature study method. The number of samples in this study were 75 respondents and it was selected by incidental sampling technique. The data analysis technique is carried out by using classic assumption test (Normality test, Multicolinearity test, and Heteroscedasticity test), multiple linear regression analysis, model feasibility test, hypothesis test, Coefficient Correlation $R$, and Multiple Determination Coefficient (R2). The result of the research shows that: (1) store atmosphere $\left(X_{1}\right)$ has significant influence to the purchase decision on Pusri Mart area Semarang; (2) Location $\left(X_{2}\right)$ has significant influence to the purchasie decision on Pusri Mart area Semarang; (3) Store atmosphere is the variable which has the most dominant influence to the purchase decision on Pusri Mart area Semarang.
\end{abstract}

Keywords: Store atmosphere, location, purchase decision.

\section{PENGARUH SUASANA TOKO DAN LOKASI TERHADAP KEPUTUSAN PEMBELIAN PADA PUSRI MART DAERAH SEMARANG}

\begin{abstract}
ABSTRAK
Tujuan penelitian ini adalah untuk menganalisis pengaruh suasana toko dan lokasi terhadap keputusan pembelian di Pusri Mart daerah Semarang. Teknik pengumpulan data dilakukan dengan menggunakan kuesioner yang dilakukan setelah uji validitas dan uji reliabilitas dilakukan, wawancara, observasi, dan studi literatur. Jumlah sampel dalam penelitian ini adalah 75 responden dan dipilih dengan teknik sampling insidental. Teknik analisis data dilakukan dengan menggunakan uji asumsi klasik (uji normalitas, uji multikolinieritas, dan uji heteroskedastisitas), analisis regresi linier berganda, uji kelayakan model, uji hipotesis, Koefisien Korelasi R, dan Koefisien Determinasi Berganda $\left(\mathrm{R}_{2}\right)$. Hasil penelitian menunjukkan bahwa: (1) suasana toko $\left(\mathrm{X}_{1}\right)$ berpengaruh signifikan terhadap keputusan pembelian di Pusri Mart daerah Semarang; (2) Lokasi $\left(\mathrm{X}_{2}\right)$ berpengaruh signifikan terhadap keputusan pembelian di Pusri Mart daerah Semarang; (3) Suasana toko adalah variabel yang memiliki pengaruh paling dominan terhadap keputusan pembelian di Pusri Mart daerah Semarang.
\end{abstract}

Kata kunci: Lokasi, Keputusan Pembelian, Suasana Toko

\section{PENDAHULUAN}

Seiring dengan perkembangan jaman, perusahaan dituntut untuk bersaing dalam bisnis, pelaku usaha yang bermain di dalam bisnis ini dituntut untuk selalu melakukan inovasi yang pada nantinya akan merebut hati konsumen dan berusaha menawarkan berbagai rangsangan yang mampu menarik minat konsumen untuk melakukan keputusan pembelian. Pusri Mart merupakan toko atau 
kios penjualan yang menyediakan berbagai jenis kebutuhan input dan output pertanian milik PT Pupuk Sriwidjaja Palembang dan Grup Perusahaan seperti pupuk, benih, pestisida, herbisida, dan sarana pertanian lainnya.

Frekuensi konsumen yang datang untuk membeli pupuk tergolong rendah $(<15 \mathrm{x}$ dalam 1 minggu), bahkan banyak dari masyarakat yang belum mengetahui Pusri Mart, kondisi tersebut menyebabkan penjualan Pusri Mart rendah $(<15 \mathrm{x}$ dalam 1 minggu), terbukti dari data yang nampak pada grafik 1.

\section{REALISASI PENJUALAN PUSRI MART} PPD JAWA TENGAH

TAHUN 2018

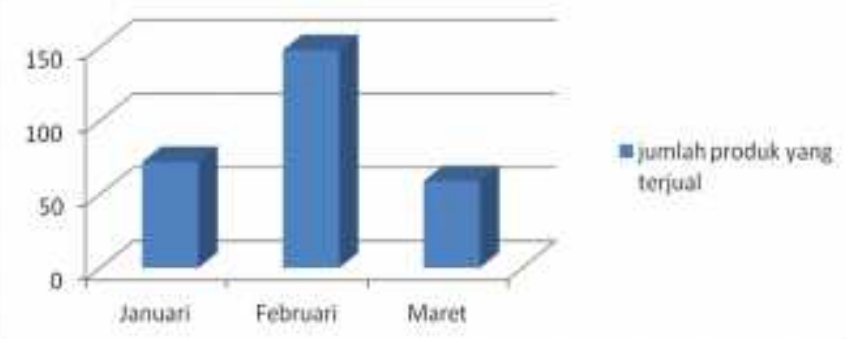

Sumber: Laporan Penjualan Pusri Mart Wilayah Semarang

Grafik 1 Realisasi Penjualan Pusri Mart Wilayah Semarang

Dari grafik 1 dapat diambil kesimpulan bahwa volume penjualan pada Pusri Mart tidak stabil dan masih tergolong rendah $(<15 \mathrm{x}$ dalam 1 minggu). Seperti pada bulan Januari dan bulan Maret 2018 Pusri Mart hanya mampu menjual kurang dari 100 produk pupuk. Salah satu yang mempengaruhi menurunnya volume penjualan pada Pusri Mart adalah keputusan pembelian, keputusan pembelian konsumen merupakan sebuah tindakan yang dilakukan konsumen untuk membeli suatu produk.

Setiap produsen pasti menjalankan berbagai strategi untuk menarik konsumen melakukan keputusan pembelian, dengan banyaknya konsumen yang melakukan keputusan pembelian pada Pusri Mart, tentunya akan memberikan dampak positif terhadap keberlangsungan Pusri Mart. Konsumen akan melakukan keputusan pembelian apabila konsumen merasa nyaman dalam berbelanja, oleh karena itu situasi pembelian terutama lingkungan fisik, seperti warna, cahaya, dan pengaturan suhu ruangan perlu di perhatikan, lingkungan fisik yang menarik diharapkan mampu menarik konsumen untuk melakukan keputusan pembelian. Salah satu faktor yang mempengaruhi keputusan pembelian adalah suasana toko tidak hanya dapat memberikan suasana lingkungan yang menarik bagi konsumen, suasana toko juga sebagai salah satu sarana komunikasi yang dapat berakibat positif dan menguntungkan, dapat dibuat semenarik mungkin dan juga dibuat agar konsumen dapat merasa nyaman dalam berbelanja.

Lokasi yang mudah di jangkau oleh konsumen dan dekat dengan target pasar merupakan lokasi yang tepat untuk menetukan usaha, apabila terjadi kesalahan dalam memilih lokasi / tempat akan berpengaruh besar terhadap siklus penjualan secara terus-menerus. Faktor lain yang mempengaruhi keputusan pembelian adalah lokasi. Pusri Mart berada di daerah kota yaitu di jalan Imam Bonjol no 208 Semarang. Sehingga bagi yang membutuhkan pupuk harus menuju ke kota, sedangkan target pasar 
utama dari Pusri Mart notabennya berasal di daerah desa. Dengan kata lain apabila suasana toko pada Pusri Mart tertata senyaman mungkin dan lokasi Pusri Mart yang strategis, maka akan mempengaruhi konsumen dalam melakukan keputusan pembelian pada Pusri Mart, hal ini didukung oleh penelitian Syahputra dan Supriyatin (2015) yang menyatakan bahwa suasana tokodan lokasi berpengaruh pada keputusan pembelian.

\section{Rumusan Masalah}

Berdasarkan pada latar belakang yang telah disebutkan, maka perumusan masalah yang diajukan dalam penelitian ini adalah:

a. Bagaimana pengaruh Suasana toko terhadap keputusan pembelian pada Pusri Mart daerah Semarang?

b. Bagaimana lokasi berpengaruh terhadap keputusan pembelian pada Pusri Mart daerah Semarang?

c. Bagaimana pengaruh Suasana toko dan lokasi terhadap keputusan pembelian pada Pusri Mart daerah Semarang?

Tujuan dan Manfaat Hasil Penelitian

Tujuan Hasil Penelitian

Didalam penelitian pastilah ada tujuan penelitian, adapun tujuan dari penelitian ini adalah:

a. Untuk menganalisis pengaruh Suasana toko terhadap keputusan pembelian pada Pusri Mart daerah Semarang

b. Untuk menganalisis pengaruh lokasi terhadap keputusan pembelian pada Pusri Mart daerah Semarang

c. Untuk menganalisis pengaruh Suasana toko dan lokasi terhadap keputusan pembelian pada Pusri Mart daerah Semarang

Manfaat Hasil Penelitian

Manfaat yang didapat dengan diadakannya peneliti ini adalah:

a. Manfaat bagi penulis

Melalui Penelitian ini penulis dapat menerapkan ilmu manajemen pemasaran serta teori- teori yang telah diperoleh di bangku perkuliahan sehingga dapat memecahkan masalah yang dihadapi dilapangan secara ilmiah.

b. Manfaat bagi Pusri Mart

Sebagai bahan masukan untuk perusahaan agar lebih memperhatikan Pusri Mart, baik Suasana toko Pusri Mart dan pemilihan lokasi Pusri Mart.

c. Manfaat bagi akademik

Dengan adanya penelitian ini dapat menambah referensi di Perpustakaan Politeknik Negeri Semarang. Dan bisa menambah wawasan bagi pembaca di perpustakaan politeknik negeri semarang

Tinjauan Pustaka

Suasana Toko

Atmosfer adalah istilah yang lebih luas dari pada tata ruang. Atmosfer berhubungan dengan bagaimana para manajer dapat memanipulasi desain bangunan, ruang interior, tata ruang lorong-lorong, dinding, bau, warna, bentuk dan suara yang dialami para pelanggan yang kesemuanya untuk mencapai pengaruh tertentu. Seperti yang dikemukakan oleh Berman et al (2018:464) "Store atmosphere (atmospherics) can be divided into these key elements: exterior, general interior, store layout, and displays" yang artinya atmosfer toko atau suasana toko (atmosfer) dapat dibagi menjadi beberapa elemen-elemen kunci yaitu : eksterior, interior umum, tata letak toko, dan display. Menurut pendapat Utami (2010:255) store atmosphere merupakan kombinasi dari karakterikstik fisik toko seperti arsitektur, tata letak, pencahayaan, pemajangan, warna, temperature, music, aroma yang secara menyeluruh akan menciptakan citra dalam benak konsumen.

\section{Lokasi}

Lokasi sangat penting bagi pelanggan dalam memutuskan keputusan pembelian, karena apabila lokasi yang ditempuh jauh dan memiliki medan yang sulit ditempuh, akan berpengaruh negatif terhadap keputusan 


\section{Sa'idah dkk/AdBis 20 (1): 61 - 74}

pembelian. Lokasi memegang peran penting dalam melakukan usaha. Menurut Tjiptono dalam Syahputra dan Supriyatin (2015:3) berpendapat bahwa lokasi adalah tempat perusahaan beroperasi atau tempat perusahaan melakukan kegiatan untuk menghasilkan barang dan jasa dengan mementingkan bagi ekonominya. Memilih lokasi yang tepat adalah suatu keharusan yang harus dipenuhi oleh perusahaan, karena bila terjadi kesalahan dalam memilih lokasi, akan menyababkan kerugian secara terus menerus pada perusahaan karena akan berpengaruh pada keputusan pembelian. Seperti yang dikemukakan oleh Suprianto dkk dalam Rizal dkk (2017:384) location can be a consumer consideration in making purchasing decisions artinya lokasi dapat menjadi pertimbangan konsumen dalam membuat keputusan pembelian.

Keputusan Pembelian

Menurut Sagata dkk dalam Rizal dkk (2017:346) the consumer purchase decision is a set of consumer choices made before making a purchase when they have a desire to buy Pengertian tersebut dapat diartikan bahwa Keputusan pembelian konsumen adalah satu set pilihan konsumen dibuat sebelum melakukan pembelian ketika mereka memiliki keinginan untuk membeli.

Sedangkan menurut Peter-Olson dalam Mulyadi Nitisusastro (2012:195) menegaskan bahwa pengambilan keputusan konsumen merupakan proses interaksi antara sikap afektif, sikap kognitif, sikap behavioral dan faktor lingkungan dengan mana manusia melakukan pertukaran dalam semua aspek kehidupannya. Menurut Suharno dalam Syahputra dan Supriyatin (2015:8-9) menyatakan bahwa keputusan pembelian konsumen adalah tahap di mana pembeli telah menentukan pilihannya dan melakukan pembelian produk, serta mengkonsumsinya. Pengertian tersebut dapat diartikan bahwa perilaku keputusan pembelian mengacu pada perilaku pembelian akhir dari konsumen, baik individual, maupun rumah tangga yang membeli barang dan jasa untuk konsumsi pribadi.

Faktor-Faktor Yang Mempengaruhi Keputusan Pembelian

Menurut Kotler dan Amstrong (2014) dalam Hermawan (2017:40-44) keputusan pembelian konsumen dipengaruhi oleh beberapa faktor, yaitu:

a) Faktor budaya

Budaya adalah penyebab paling mendasar dari keinginan dan perilaku seseorang. Perilaku manusia sebagian besar dipelajari. Tumbuh dalam masyarakat, seorang anak belajar nilai dasar, persepsi, keinginan, dan perilaku dari keluarganya dan institusi penting lainnya. Masing-masing subbudaya terdiri dari sejumlah sub-budaya yang lebih menampakkan identifikasi dan sosialisasi khusus bagi para anggotanya seperti kebangsaan, agama, kelompok, ras, dan wilayah geografis atau lokasi.

Penelitian ini membahas tentang lokasi yang termasuk dalam faktor budaya. Lokasi akan berpengaruh positif terhadap keputusan pembelian apabila memudahkan konsumen dalam membeli produk, dalam segi akses, tempat parkir, lokasi yang strategis dan lain sebagainya.

b) Faktor Sosial

Perilaku konsumen juga dipengaruhi oleh faktor sosial, seperti kelompok kecil, keluarga, dan peran sosial konsumen.

c) Kelompok dan Jaringan sosial

Banyak kelompok kecil mempengaruhi perilaku seseorang. Kelompok yang meninggalkan pengaruh langsung dan yang dimiliki seseorang disebut kelompok anggota kelompok.

d) Keluarga

Anggota keluarga dapat sangat mempengaruhi perilaku pembeli. Keluarga adalah organisasi konsumen yang paling penting dalam masyarakat, dan telah diteliti secara ekstensif

e) Peran dan Status

Seseorang termasuk dalam banyak kelompok - keluarga, klub, organisasi, 
komunitas online. Posisi orang di setiap kelompok dapat didefinisikan dalam hal peran dan status. Peran terdiri dari kegiatan yang diharapkan orang tampil sesuai dengan orang disekitarnya.

f) Faktor Pribadi

Keputusan pembeli juga dipengaruhi oleh karakteristik pribadi seperti usia pembeli dan tahap siklus hidup, pekerjaan, situasi ekonomi, gaya hidup, dan kepribadian dan konsep diri.

(1) Umur dan Siklus hidup

Orang mengubah barang dan jasa yang mereka beli seumur hidup mereka. Selera makanan, pakaian, furnitur, dan rekreasi sering dikaitkan dengan usia.

(2) Pekerjaan

Pekerjaan seseorang mempengaruhi barang dan jasa yang dibeli. Pekerja kerah biru cenderung membeli pakaian kerja yang lebih kasar, sementara para ekslusif membeli lebih banyak setelan bisnis.

(3) Situasi Ekonomi

Situasi ekonomi seseorang akan mempengaruhi pilihan toko dan produknya. Pemasar melihat tren pendapatan pribadi, tabungan, dan tingkat suku bunga. Pada saat yang lebih hemat setelah resesi besar, kebanyakan perusahaan telah mengambil langkah untuk mendesain ulang, memposisikan ulang, dan mengembalikan produk dan layanan mereka.

(4) Gaya Hidup

Orang-orang yang berasal dari subkultur, kelas sosial, dan pekerjaan yang sama mungkin memiliki gaya hidup yang sangat berbeda adalah pola hidup seseorang seperti yang diungkapkan dalam psikografnya. Suasana Toko termasuk dalam faktor gaya hidup, setiap kelas sosial pastinya memiliki gaya hidup dan pilihan store yang sesuai dengan gaya hidupnya, sebagai contohnya apabila kelas sosial menengah keatas, cenderung memilih store yang memiliki suasana toko yang nyaman, dengan harga yang relative lebih mahal. Namun untuk menjadi store pilihan tentunya dibutuhkan suasana toko yang mampu menarik pelanggan dan mampu memberikan kesan positif terhadap konsumen, sehingga berpengaruh terhadap pengambilan keputusan konsumen.

(5) Kepribadian dan Konsep diri

Kepribadian masing-masing orang mempengaruhi perilaku belanjanya. Kepribadian mengacu pada karakteristik psikologis unik yang membedakan seseorang atau grup.

\section{METODE}

Populasi

Menurut Sugiyono (2014:115) populasi adalah wilayah generalisasi yang terdiri atas obyek/subyek yang mempunyai kualitas dan karakteristik tertentu yang ditetapkan oleh peneliti untuk dipelajari dan kemudian ditarik kesimpulannya. Populasi dalam penelitian ini adalah konsumen yang sudah pernah membeli produk di Pusri Mart yaitu sebanyak 295 pelanggan.

Sample

Menurut Sugiyono (2014:116) Sampel dapat didefinisikan sebagai bagian dari jumlah dan karakterikstik yang dimiliki oleh populasi tersebut. Apabila jumlah populasi diketahui secara jelas jumlahnya maka dapat digunakan beberapa rumus atau tabel. Salah satu rumus yang sering digunakan adalah rumus slovin (Wijaya, 2013:29). Jumlah sampel ditentukan berdasarkan perhitungan dari rumus slovin dengan tingkat kesalahan $10 \%$. Dari rumus slovin, didapat hasil sebanyak 74,683 dibulatkan menjadi 75 orang sebagai sampel dari populasi sebanyak 295 pelanggan yang pernah membeli di Pusri Mart.

Teknik Pengumpulan Data

Metode pengumpulan data yang digunakan dalam Skripsi ini adalah sebagai berikut:

a. Kuesioner 
Menurut Sugiyono (2014:199), kuesioner merupakan teknik pengumpulan data yang dilakukan dengan cara memberi seperangkat pertanyaan atau pernyataan tertulis kepada responden untuk menjawabnya.

b. Wawancara (interview)

Menurut Sugiyono (2014:194) wawancara digunakan sebagai teknik pengumpulan data, apabila peneliti ingin melakukan studi pendahuluan untuk menemukan permasalahan yang harus diteliti, dan juga apabila peneliti ingin mengetahui hal-hal dari responden yang lebih mendalam dan jumlah respondennya sedikit/kecil.

c. Observasi

Seperti dikatakan oleh Sugiyono (2014:203) observasi memiliki ciri yaitu tidak terbatas pada orang tetapi juga obyek-obyek alam yang lain beda dengan wawancara dan kuesioner yang melibatkan orang, observasi digunakan berkenaan dengan perilaku manusia, proses kerja, gejala-gejala alam

d. Metode Studi Pustaka

Studi pustaka adalah salah satu cara untuk mengumpulkan data yang dilakukan dengan mempelajari literature-literatur dan buku-buku bacaan yang berhubungan dengan penelitian ini.

\section{Jenis Data}

Jenis data yang digunakan dalam Skripsi ini ada 2 yaitu data kualitatif dan data kuantitatif, berikut penjelasannya:

a. Data kualitatif

Data kualitatif menurut Sujarweni (2015:82) dapat disebut data hasil kategori (pemberian kode) untuk isi data yang berupa kata. lebih lanjut

b. Data Kuantitatif

Data kuantitatif menurut Sujarweni (2015: 83) adalah data yang berupa angka dalam arti sebenarnya.

Sumber Data
Sumber data pada penelitian ini ada 2 yaitu sumber primer dan sumber sekunder, berikut penjelasannya:

a. Sumber Primer

Menurut Sugiyono (2014:193) sumber primer adalah sumber data yang langsung memberikan data kepada pengumpul data. Dengan kata lain sumber data primer merupakan data yang didapatkan langsung oleh penulis tanpa perantara.

b. Sumber Sekunder

Data sekunder merupakan sumber yang tidak langsung memberikan data kepada pengumpul data, misalnya lewat orang lain atau lewat dokumen (Sugiyono, 2014:193). Dengan kata lain data yang didapatkan penulis melalui perantara.

Teknik Sampling

Teknik sampling yaitu teknik yang digunakan dalam pengambilan sampel, teknik sampling yang digunakan yaitu menggunakan non probability sampling dengan teknik sampling insidental. Menurut Sugiyono (2014:118) sampling insidental adalah teknik penentuan sampel berdasarkan kebetulan, yaitu siapa saja yang secara kebetulan/incidental bertemu dengan peneliti dapat digunakan sebagai sampel, bila dipandang orang yang kebetulan tersebut ditemui dan cocok sebagai sumber data.

Alat Analisis Intrumen Data

Uji Validitas dan Uji Reliabilitas

1) Uji Validitas

Menurut Ghozali (2016:52) Suatu kuesioner dikatakan valid jika pertanyaan pada kuesioner mampu untuk mengungkapkan sesuatu yang akan diukur oleh kuesioner tersebut.

2) Uji Reliabilitas

Uji reliabilitas terhadap item-item pertanyaan dari kuesioner digunakan untuk mengukur kehandalan atau konsistensi dari instrument penelitian. Menurut Ghozali pada Syahputra (2015:12) suatu konstruk atau variabel 
dapat dikatakan reliable jika memberikan nilai cronbach alpha $(\alpha)>0.60$.

\section{Uji Asumsi Klasik}

Pengujian asumsi klasik dilakukan untuk mengetahui kondisi data yang ada agar dapat menentukan model análisis yang tepat. Data yang digunakan sebagai model regresi berganda dalam menguji hipotesis haruslah menghindari kemungkinan terjadinya penyimpangan asumsi klasik.

3) Uji Normalitas

Menurut Gujarati dan Porter dalam Syahputra (2015:14) uji normalitas bertujuan untuk menguji apakah dalam model regresi data telah memenuhi persyaratan distribusi normal dan apakah residual dalam model regresi sudah terdistribusi secara normal.

4) Uji Multikolonieritas

Uji multikolonieritas bertujuan untuk menguji apakah model 2 regresi ditemukan adanya korelasi antar variabel bebas (independen) (Ghozali, 2016:103.

5) Uji Heteroskedastisitas

Menurut Ghozali (2016:134) uji heteroskedastisitas bertujuan untuk menguji apakah dalam model regresi terjadi ketidaksamaan variance dari residual satu pengamatan ke pengamatan lain.

Teknik Analisis Data

Analisis Regresi Linier Berganda

Analisis regresi ganda bertujuan untuk mengetahui hubungan 1 variabel dependen dengan 2 atau lebih variabel independen. Seperti yang dikemukakan oleh Ridwan dalam Syahputra $(2015,15)$ analisis regresi linier berganda adalah suatu prosedur statistik dalam menganalisis pengaruh antara variabel bebas (X) terhadap variabel terikat (Y), dengan Formula untuk regresi linier berganda adalah sebagai berikut:

$\mathrm{Y}=\mathrm{a}+\mathrm{b} 1 \mathrm{X} 1+\mathrm{b} 2 \mathrm{X} 2+\mathrm{e}$

Keterangan:

$\mathrm{Y}=$ Keputusan Pembelian

$\mathrm{a}=$ Konstanta
$\mathrm{X} 1=$ Suasana toko

$\mathrm{X} 2$ = Lokasi

b1 = Koefisien regresi untuk variabel suasana toko

b2 $=$ Koefisien regresi untuk variabel lokasi

e $=$ Error

Uji Hipotesis

1) Uji Signifikasi Simultan (Uji F)

Uji $\mathrm{F}$ digunakan untuk menguji kelayakan model penelitian. Menurut Ferdinand dalam Syahputra (2015:15) model dikatakan layak apabila hasil pengolahan dari SPSS nilai signifikansi $<0,05$ selain dilihat dari signifikansi juga dapat dilihat dengan mekanisme pengujiannya apabila $\mathrm{F}_{\text {hitung }}>\mathrm{F}_{\text {tabel }}$ maka $\mathrm{H}_{\mathrm{a}}$ diterima dan $\mathrm{H}_{0}$ ditolak. Sebaliknya $\mathrm{F}_{\text {hitung }}<\mathrm{F}_{\text {tabel }}$ maka $\mathrm{H}_{0}$ diterima dan $\mathrm{H}_{\mathrm{a}}$ ditolak (Ghozali, 2016:96).

2) Uji Signifikasi Parameter Individual (Uji t) Uji statistik t pada dasarnya menunjukkan seberapa jauh pengaruh satu variabel penjelas/independent secara individual dalam menerangkan variasi variabel dependen (Ghozali, 2016:97).

Koefisien Determinasi $\left(\mathrm{R}^{2}\right)$

Koefisien determinasi menurut Kuncoro dalam Syahputra (2015:16) adalah untuk mengukur seberapa jauh kemampuan model dalam menerangkan variasi variabel. Nilai koefisien determinasi adalah antara nol dan satu (Ghozali, 2016:95).

\section{HASIL DAN PEMBAHASAN}

Uji Validitas dan Reliabilitas

Uji Validitas

Untuk mengetahui valid tidaknya suatu kuesioner menurut Sujarweni (2015: 160) dengan cara membandingkan antara $r_{\text {hitung }}$ dan $\mathrm{r}_{\text {tabel}}$, dimana $\mathrm{df}=\mathrm{n}-2$ dengan sig 5\%. Jika $\mathrm{r}_{\text {tabel }}$ $<\mathrm{r}_{\text {hitung }}$ maka valid. Dengan $: \mathrm{n}=30$, dan $\mathrm{df}=$ n-2

$$
\begin{aligned}
& \text { df }=30-2 \\
& \text { df }=28
\end{aligned}
$$

Berdasarkan hasil perolehan $\mathrm{r}_{\text {tabel }}$ untuk nilai $\mathrm{n}$ $=30$, dapat dilihat pada kolom $r_{\text {tabel }}$ dengan signifikansi $5 \%$ adalah 0.361. Seluruh pertanyaan untuk variabel dapat dinilai 
apabila $\mathbf{r}_{\text {hitung }}$ (hasil perhitungan dalam program SPSS) lebih besar dari $r_{\text {tabel }}$ maka dapat dikatakan hasil tersebut valid, dan apabila $r_{\text {hitung }}$ (hasil perhitungan SPSS) lebih kecil dari $\mathrm{r}_{\text {tabel }}$ maka dapat dikatakan hasil tersebut tidak valid. Dapat diketahui bahwa seluruh indikator masing-masing variabel memiliki $r_{\text {hitung }}$ yang lebih besar dari $r_{\text {tabel, }}$ sehingga dapat disimpulkan seluruh pertanyaan-pertanyaan yang digunakan tergolong valid dan layak dijadikan instrument penguji dalam penelitian yang akan disebarkan pada responden.

Uji Reliabilitas

Menurut Ghozali pada Syahputra (2015:12) suatu konstruk atau variabel dapat dikatakan reliable jika memberikan nilai cronbach alpha $(\alpha)>0.60$. Hasil uji reliabilitas nilai cronbach alpha $(\alpha)$ dapat dilihat pada tabel 1.

Tabel 1 Ringkasan Hasil Uji Reliabilitas

\begin{tabular}{lccc}
\hline \multicolumn{1}{c}{ Variabel } & $\begin{array}{c}\text { Cronbach } \\
\text { Alpha }(\boldsymbol{\alpha})\end{array}$ & $\begin{array}{c}\text { Koefisien } \\
\text { Alpha }\end{array}$ & Keterangan \\
\hline Suasana toko X1 & 0,710 & 0,60 & Reliabel \\
Lokasi X2 & 0,678 & 0,60 & Reliabel \\
Keputusan Pembelian Y & 0,831 & 0,60 & Reliabel \\
\hline
\end{tabular}

Sumber data primer yang diolah, 2018

Berdasarkan pada tabel 1 bisa dijelaskan cronbach alpha $(\alpha)$ pada seluruh variabel lebih besar dari 0.6 hal ini berarti seluruh variabel dinyatakan reliabel dan absah dalam penelitian.

Uji Asumsi Klasik

Uji Normalitas
Menurut Gujarati dan Porter dalam Syahputra (2015:14) uji normalitas bertujuan untuk menguji apakah dalam model regresi data telah memenuhi persyaratan distribusi normal dan apakah residual dalam model regresi sudah terdistribusi secara normal. Penelitian ini menggunakan uji Kolmogorov-Smirnov (K-S) yang diolah pada software SPSS versi 22.

Tabel 2 Ringkasan Hasil Uji Normalitas

\begin{tabular}{llr}
\multicolumn{2}{c}{ One-Sample Kolmogorov-Smirnov Test } \\
\hline $\mathrm{N}$ & $\begin{array}{c}\text { Unstandardized } \\
\text { Residual }\end{array}$ \\
\hline Normal Parameters ${ }^{\text {a,b }}$ & Mean & 75 \\
Most Extreme Differences & Std. Deviation & .0000000 \\
& Absolute & 4.39313132 \\
Test Statistic & Positive & .088 \\
Asymp. Sig. (2-tailed) & Negative & .069 \\
\hline a. Test distribution is Normal. & & -.088 \\
b. Calculated from data. & & .088 \\
c. Lilliefors Significance Correction. & $.200^{\text {c,d }}$ \\
d. This is a lower bound of the true significance. & \\
Sumber data primer yang diolah, &
\end{tabular}

Sumber data primer yang diolah, 2018 
Berdasarkan tabel 2 dapat dikatakan bahwa data berdistribusi normal karena pada most ektreme differences absolute didapat nilai sebesar 0,088 apabila dibandingkan dengan kolmogorov tabel pada sample $\mathrm{N}=75$ dengan $\alpha=0,05$ yaitu 0,154 , maka $0,088<0,154$. Hal ini dibuktikan dengan hasil uji probabilitas pada SPSS yaitu didapatkan nilai sebesar 0,200 pada Asymp. Sig. (2 tailed) maka $0,2>0,05$.

Uji Multikolonieritas
Pengujian multikolonieritas pada penelitian ini dilakukan dengan melihat nilai dari Variance Inflation Factor (VIF) dan Tolerance yang dapat mengidentifikasi ada tidaknya masalah multikolonieritas. Nilai cutoff yang dipakai untuk menunjukkan adanya multikolonieritas adalah nilai tolerance $₫, 10$ atau sama dengan nilai VIF $\geq 10$ (Ghozali, 2016:104). Berdasarkan hasil olah SPSS versi 22 uji multikolonieritas dapat dijelaskan pada tabel 3.

Tabel 3 Hasil Uji Multikolonieritas

\begin{tabular}{|c|c|c|c|c|}
\hline \multicolumn{5}{|c|}{ Coefficients } \\
\hline \multicolumn{3}{|c|}{ Correlations } & \multicolumn{2}{|c|}{ Collinearity Statistics } \\
\hline Zero-order & Partial & Part & Tolerance & VIF \\
\hline .450 & .390 & .349 & .937 & 1.068 \\
\hline .447 & .386 & .345 & .937 & 1.068 \\
\hline
\end{tabular}

Sumber data primer yang diolah, 2018

Dari tabel 3 dapat diketahui pada coefficients diperoleh nilai Variance Inflation Factor (VIF) suasana toko (X1) sebesar 1,168, Lokasi (X2) sebesar 1,168. Hasil perhitungan menunjjukkan tidak ada satu variabel independen yang memiliki nilai Variance Inflation Factor (VIF) $\geq 10$. Nilai Tolerance suasana toko (X1) sebesar 0,937, lokasi (X2) sebesar 0,937 artinya nilai Tolerance seluruh variabel independen $\leq 0,10$. Dari perhitungan tersebut maka dapat disimpulkan bahwa model regresi yang digunakan pada penelitian ini dianggap tidak memiliki masalah multikolonieritas.

Uji Heteroskedastisitas

Deteksi ada tidaknya heteroskedastisitas dapat dilihat dari pada grafik scatterplot.

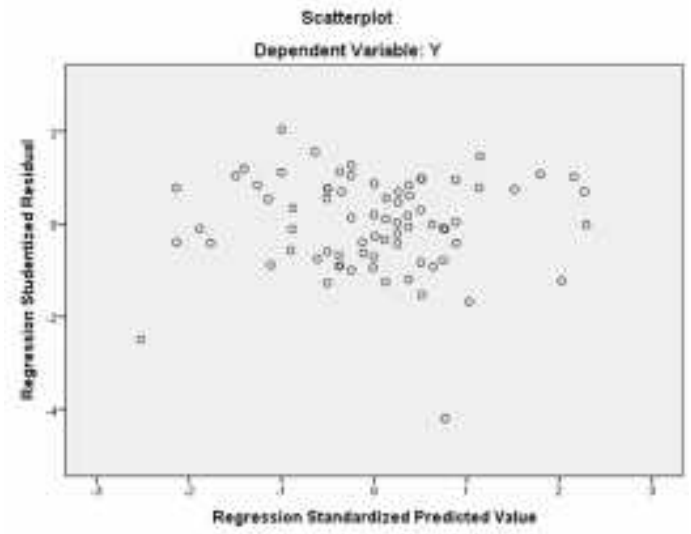

Sumber data primer yang diolah, 2018

Gambar 1 Hasil Uji Heteroskedastisitas 
Jika tidak ada pola yang jelas, serta titik-titik menyebar diatas dan dibawah angka 0 pada sumbu $y$, maka tidak terjadi heteroskedastisitas. Model regresi yang baik adalah yang homokesdastisitas atau tidak terjadi heteroskedastisitas (Ghozali, 2016:134). Berdasarkan hasil olah SPSS versi 22 uji heteroskedastisitas pada gambar 1. Dari grafik Scatterplot terlihat bahwa titik-titik menyebar secara acak serta tersebar baik di atas maupun di bawah angka 0 pada sumbu Y. Hal ini dapat disimpulkan bahwa tidak terjadi heteroskedastisitas pada model regresi, sehingga model regresi layak dipakai untuk penelitian ini.

Analisis Regresi Linier Berganda

Analisis statistik yang digunakan dalam penelitian ini yaitu analisis regresi linier berganda untuk menganalisis pengaruh suasana toko (X1) dan lokasi (X2) terhadap keputusan pembelian (Y). Adapun hasil olah data dengan menggunakan SPSS versi 22 dapat dilihat pada tabel 4 .

Tabel 4 Hasil Analisis Regresi

Coefficients $^{\mathrm{a}}$

\begin{tabular}{|c|c|c|c|c|c|c|}
\hline \multirow{2}{*}{\multicolumn{2}{|c|}{ Model }} & \multicolumn{2}{|c|}{ Unstandardized Coefficients } & Standardized Coefficients & \multirow[b]{2}{*}{$\mathrm{T}$} & \multirow[b]{2}{*}{ Sig. } \\
\hline & & $\mathrm{B}$ & Std. Error & Beta & & \\
\hline 1 & (Constant) & .502 & 6.299 & & .080 & .937 \\
\hline & $\begin{array}{l}X 1 \\
X 2\end{array}$ & $\begin{array}{l}378 \\
.386\end{array}$ & $\begin{array}{l}.105 \\
.109\end{array}$ & $\begin{array}{l}.360 \\
.357\end{array}$ & $\begin{array}{l}3.594 \\
3.555\end{array}$ & $\begin{array}{l}.001 \\
.001\end{array}$ \\
\hline
\end{tabular}

a. Dependent Variable: $Y$

Sumber data primer yang diolah, 2018

Berdasarkan tabel 4, analisis regresi dapat diketahui persamaan regresi yaitu:

$Y=0,502+0,378 X_{1}+0,386 X_{2}$

Keterangan

$\mathrm{Y}=$ Keputusan pembelian

$\mathrm{X}_{1}=$ Suasana toko

$\mathrm{X}_{2}=$ Lokasi

Dari persamaan regresi diatas dapat diinterprestasikan sebagai berikut:

1) a sebesar 0,502 artinya jika variabel bebas yang terdiri dari suasana toko dan lokasi nilainya 0 , maka variabel keputusan pembelian akan bernilai sebesar 0,502 .

2) Koefisien regresi suasana toko $\left(X_{1}\right)$ sebesar 0,378, dengan tingkat signifikansi sebesar 0,01. Hal ini berarti setiap peningkatan variabel suasana toko akan meningkatkan keputusan pembelian sebesar 0,378 pada Pusri Mart. Hasil ini menunjukkan bahwa suasana toko berpengaruh terhadap keputusan pembelian.
3) Koefisien regresi Lokasi $\left(X_{2}\right)$ sebesar 0,386, dengan tingkat signifikansi sebesar 0,01 . Hal ini berarti setiap peningkatan variabel lokasi akan meningkatkan keputusan pembelian sebesar 0,386 pada Pusri Mart. Hasil ini menunjukkan bahwa lokasi berpengaruh terhadap keputusan pembelian.

4) Persamaan regresi tersebut, dapat disimpulkan bahwa variabel paling dominan berpengaruh terhadap variabel keputusan pembelian adalah variabel lokasi dengan nilai koefisien sebesar 0,386 .

Uji Signifikansi

Uji Signifikansi Simultan (Uji F)

Mekanisme pengujiannya apabila $F_{\text {hitung }}>F_{\text {tabel }}$ maka $\mathrm{HA}$ diterima dan $\mathrm{H}_{0}$ ditolak. Sebaliknya $\mathrm{F}_{\text {hitung }}<\mathrm{F}_{\text {tabel }}$ maka $\mathrm{H}_{0}$ diterima dan HA ditolak (Ghozali, 2016:96). Berdasarkan tabel 5, menunjukkan bahwa $F_{\text {hitung }}$ sebesar 17,071 sedangkan $F_{\text {tabel }}$ sebesar 3,123 artinya $F_{\text {hitung }}>$ $\mathrm{F}_{\text {tabel }}$ maka $\mathrm{HA}$ diterima dan $\mathrm{H} 0$ ditolak dengan tingkat signifikansi sebesar 0,000 < 0,05. Maka dapat disimpulkan variabel 
independen yaitu suasana toko dan lokasi secara simultan atau bersama-sama berpengaruh signifikan terhadap variabel dependen yaitu keputusan pembelian Pusri Mart daerah Semarang.

Tabel 5 Hasil Uji Signifikansi Simultan F

\begin{tabular}{lrrrrrr}
\multicolumn{7}{c}{ ANOVA $^{\mathrm{a}}$} \\
\hline Model & Sum of Squares & Df & Mean Square & F & Sig. \\
\hline 1 & Regression & 677.216 & 2 & 338.608 & 17.071 & $.000^{\mathrm{b}}$ \\
& Residual & 1428.171 & 72 & 19.836 & & \\
& Total & 2105.387 & 74 & & & \\
\hline
\end{tabular}

a. Dependent Variable: $Y$

b. Predictors: (Constant), X2, X1

Sumber data primer yang diolah, 2018

Uji Signifikansi Parameter Individual (Uji t) Uji t digunakan untuk mengetahui pengaruh masing-masing variabel bebas (X) terhadap variabel terikat $(\mathrm{Y})$. Uji t dilakukan dengan cara membandingkan nilai $t_{\text {hitung }}$ dengan nilai $\mathrm{t}_{\text {tabel }}$ dengan menggunakan taraf signifikansi 0,05 atau $5 \%$.

Pengaruh variabel suasana toko $\left(\mathrm{X}_{1}\right)$ dan lokasi $\left(\mathrm{X}_{2}\right)$ terhadap keputusan pembelian $(\mathrm{Y})$ pada Pusri Mart:

$\mathrm{H}_{0} 1$ : Tidak ada pengaruh antara suasana toko terhadap keputusan pembelian pada Pusri Mart .

$\mathrm{H}_{0} 2$ : Tidak ada pengaruh antara Lokasi terhadap keputusan pembelian pada Pusri Mart .

$\mathrm{H}_{\mathrm{a}} 1$ : Ada pengaruh antara suasana toko terhadap Keputusan pembelian pada Pusri Mart .

$\mathrm{H}_{\mathrm{a}} 2$ : Ada pengaruh antara lokasi terhadap Keputusan pembelian pada Pusri Mart.

Dari hasil perhitungan pada tabel 4 variabel suasana toko $\left(\mathrm{X}_{1}\right)$ memiliki thitung sebesar
3,594 dengan tingkat signifikansi 0,001 apabila dilihat pada tabel $\mathrm{t}$ dengan $\alpha=05$, dan derajat kebebasan $(\mathrm{df})=\mathrm{n}-\mathrm{k}=75-3=72$ diperoleh $t_{\text {tabel }}$ sebesar 1,666. Hal ini karena 3,594 > 1,666 dan 0,001 < 0,05 maka dengan demikian $\mathrm{H}_{0}$ ditolak dan $\mathrm{H}_{\mathrm{a}}$ diterima. Kesimpulan: Suasana toko secara parsial mempunyai pengaruh yang signifikan terhadap keputusan pembelian pusri mart daerah Seamarang.

Pada variabel kedua yaitu lokasi $\left(\mathrm{X}_{2}\right)$

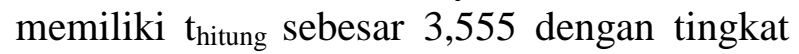
signifikansi 0,001. apabila dilihat pada tabel $\mathrm{t}$ dengan $\alpha=0,05$, dan derajat kebebasan (df) $=\mathrm{n}-\mathrm{k}=75-3=72$ diperoleh $\mathrm{t}_{\text {tabel }}$ sebesar 1,666. Hal ini karena 3,555 > 1,666 dan 0,001 $<0,05$ maka $\mathrm{Ha}$ diterima dan $\mathrm{H}_{0}$ ditolak. Kesimpulan: Lokasi secara parsial mempunyai pengaruh yang signifikan terhadap keputusan pembelian pusri mart daerah Semarang.

Koefisien Determinasi

Tabel 6 Hasil Koefisien Determinasi

\begin{tabular}{|c|c|c|c|}
\hline \multicolumn{4}{|c|}{ Model Summary ${ }^{\mathrm{b}}$} \\
\hline & & Adjusted R & \\
\hline Model & R Square & Square & Std. Error of the Estimate \\
\hline 1 & .322 & .303 & 4.454 \\
\hline $\begin{array}{l}\text { a. Pred } \\
\text { b. Dep }\end{array}$ & $\begin{array}{l}\text { nstant), X2, X1 } \\
\text { iable: } Y\end{array}$ & & \\
\hline Sumbe & imer yang diolah, & & \\
\hline
\end{tabular}

Hasil perhitungan regresi, sebagaimana Tabel 6 , dapat diketahui dari kolom $R$ Square yaitu sebesar 0,322. Hal ini berarti 32,2\% keputusan pembelian dapat ditentukan atau 


\section{Sa'idah $d k k / A d B i s ~ 20(1): 61$ - 74}

disumbankan oleh suasana toko dan lokasi dan sisanya $(100 \%-32,2 \%=67,8 \%) 67,8 \%$ ditentukan oleh variabel-variabel lain yang tidak dijelaskan dalam model regresi ini.

\section{KESIMPULAN}

Berdasarkan hasil dan pembahasan dalam penelitian Skripsi ini, dapat disimpulkan mengenai pengaruh suasana toko dan lokasi terhadap keputusan pembelian Pusri Mart daerah Semarang adalah sebagai berikut:

a. Suasana toko berpengaruh signifikan terhadap keputusan pembelian dengan nilai koefisien regresi sebesar 0,378 dan signifikan 0.001 .

b. Lokasi berpengaruh signifikan terhadap keputusan pembelian dengan nilai koefisien regresi 0,386 dan signifikan 0,001 .

c. Suasana toko dan lokasi secara simultan berpengaruh dan signifikan terhadap keputusan pembelian dengan persamaan $Y=0,502+0,378 X_{1}+0,386 X_{2}$.

d. Variabel yang memiliki pengaruh paling dominan terhadap keputusan pembelian adalah lokasi dengan nilai beta sebesar 0,386. Hal ini berarti bahwa variabel lokasi berpengaruh meningkatkan tingkat keputusan pembelian dibandingkan variabel suasana toko .

\section{Saran}

Berdasarkan hasil analisis maka saran yang bisa diberikan adalah:

a. Disarankan Pusri Mart menjadikan variabel yang memiliki pengaruh paling dominan terhadap keputusan pembelian yaitu lokasi sebagai prioritas dalam pertimbangan upaya menarik pelanggan, dengan cara membuat papan tanda lebih besar ditepi jalan, agar memudahkan konsumen menemukan pusri mart, dan menambah lahan parkir agar konsumen yang berbelanja bisa dengan mudah memarkir kendaraannya.

b. Pusri mart sebaiknya juga memperhatikan suasana toko dalam upaya menarik pelanggan atau promosi agar konsumen tertarik melakukan keputusan pembelian di Pusri Mart daerah Semarang, dengan cara antara lain menambah pencahayaan/lampu, menambah AC untuk meningkatkan kenyamanan konsumen, dan memperluas area Toko Pusri Mart, agar pembeli dengan mudah membeli produk, tanpa harus berdesakan serta menata produk dengan rapi agar bisa terlihat oleh konsumen.

c. Bagi peneliti lain diharapkan penelitian ini dapat dijadikan referensi untuk penelitian berikutnya, melalui pengembangan variabel, indikator, dan sampel.

\section{DAFTAR PUSTAKA}

Berman, barry, Evans, R. Joel \& Chatterjee Patrali. 2018. Retail Management A Strategic Approach. United kingdom : person education limited

Ferdinand, Augusty. 2014. Metode Penelitian Manajemen, pedoman penelitian untuk penulisan skripsi, tesis, dan disertasi ilmu manajemen.Semarang:Penerbit Undip

Ghozali, Imam. 2016. Aplikasi Analisis Multivariate Dengan Program IBM SPSS 20. Semarang: Badan Penerbit Universitas Diponegoro

Hermawan, Sonny. 2017. Pengaruh Promosi Dan Lokasi Terhadap Keputusan Pembelian (Studi kasus pada konsumen cafe Imah B abaturan). (tidak diterbitkan untuk umum).

http://www.pusri.co.id. (15 Juli 2018).

Mulyadi, Nitisusastro. 2012. Perilaku Konsumen Dalam Perspektif Kewirausahaan. Bandung:Alfabeta

Rizal, Fachrul. Adam, Muhammad. Ibrahim, Mahdani. 2017. Effect Of Price, Design And Location On Deceision Of Purchase And Its Implication On Customer Satisfaction. International Journal Of Economics, Commerce And Manajemen. Vol. 5. No 12.

Sugiyono. 2014. Metode Penelitian Bisnis (Pendekatan Kuantitatif, Kualitatif, dan $R \& D)$. Bandung : Alfabeta. 
Sujarweni, V Wiratna. 2015. Statistik Untuk Bisnis Ekonomi. Yogyakarta : Pustaka Baru Press.

Sujarweni,V. Wiratna.2015.Metodologi Penelitian Bisnis \&Ekonomi.Yogyakarta: PT.Pustaka Baru

Syahputra Eka Denny \& Supriyatin. 2015. Pengaruh Store Atmosphere, Harga Dan Lokasi Terhadap Keputusan Pembelian
Ori Premium. Jurnal Ilmu dan Riset Manajemen. Vol. 4, No. 11.

Tjiptono, Fandy \& Chandra, Gregorius. 2016. Service Quality \& Satisfaction, Edisi 4. Yogyakarta: Andi.

Utami, Widya Christina. 2010. Manajemen Ritel Strategi Dan Implementasi Operasional Ritel Modern Di Indonesia, Edisi 2. Jakarta : Selemba Empat. 
Sa'idah dkk/AdBis 20 (1): 61 - 74 